\title{
A legitimidade do Estado diante das mudanças econômicas e políticas estruturais contemporâneas
}

\author{
Gerardo Clésio Maia Arruda
}

\begin{abstract}
Resumo: Este artigo objetiva apreender, alicerçado na estrutura conceitual de Max Weber, as determinações da crise de representatividade política que hoje atinge os Estados-nacionais dos mais variados estágios de desenvolvimento e espectros políticos, bem como intenciona especular acerca dos limites que a realidade atual impõe ao pensamento weberiano. Com base na categoria de dominação racional-legal, busca-se, numa abordagem metodológica histórico-estrutural, explicitar os elementos fundantes da legitimidade do poder político no transcurso da modernidade e as transformações emergidas na sua lógica de funcionamento. Discute-se a burocracia como ideal tipo de organização presente em todas as dimensões de sociabilidade; também, salientam-se as transformações econômicas e políticas que ocorrem no interior e no exterior dos Estados-nações que colocam em xeque a burocracia consagrada no ápice da modernidade. Conclui-se que a teoria da dominação racional-legal ainda contém fundamentos capazes de conduzir ao entendimento dos fatores de legitimação do poder político, mas se faz mister a adequabilidade de seus marcos conceituais visando à reflexão analítica da instituição do poder e de sua legitimidade na contemporaneidade.
\end{abstract}

Palavras-chave: Estado de Direito. Legitimidade. Dominação Legal. Max Weber.

\section{The legitimacy of the state in face of economic and political contemporary structural changes}

\begin{abstract}
This article goals to seize, conceptual Max Weber structure rooted, political crises representativeness determinations which, today, reach the widest development stage and political spectrum variety within statenations, as well as intend to speculate regarding Weberian thinking imposition by nowadays reality limits. Based on rational-legal domination category, seeking on a structured-historical methodological approach, political power founding legitimacy established elements on modernity order and their functionality logic emerged specifying transformation. Debates bureaucracy as in every sociable sphere present organization ideal model; also, points out political and economic transformations that occur inside and outside statenations that pose a threat to modernity peak consecrated bureaucracy. It is concluded rational-legal dominate theory, still, has able conducting fundaments to political power factors understanding, although particularly important adequacy to conceptual marks aiming analytic, power institution and its contemporary legitimacy, reflection.
\end{abstract}

Keywords: Constitutional State. Legitimacy. Legal Domination. Max Weber.

\section{Introdução}

A modernidade compreendida a partir da utopia europeia do iluminismo conduz a salientar, como princípio fundante, a universalização da razão. De fato, o cientificismo foi se plasmando por todos os domínios da vida social até a sua consagração no final do século XIX. A ciência e a técnica aplicada à produção ocasionaram a ampliação da produtividade com base na especialização do trabalho e no desenvolvimento das forças de produção; por outro lado, a racionalização e o pensamento científico também se encontram na base da constituição do Estado moderno, por intermédio da produção normativa alicerçada na técnica e na separação especializada dos poderes.

Este processo histórico instituidor da modernidade e, simultaneamente, edificador da empresa capitalista e do direito racional, que possibilitam a segurança e a previsibilidade viabilizadora do progresso permanente do conhecimento, da riqueza e das liberdades individuais, formulou, em sua trajetória, o Estado de bem-estar, em que a legitimidade do Estado passou a ser alicerçada na 
condução das ações estatais em conformidade com a legislação em vigor e, principalmente, na capacidade de corresponder às expectativas oriundas da comunidade.

Mas, como assevera Rouanet (1992), a modernidade econômica, no último quartel do século $\mathrm{XX}$, deu sinais de esgotamento na medida mesma em que a produção industrial, base sobre a qual se assentou a modernidade, passou a ser ultrapassada pelo setor terciário. Assiste-se, desde então, à substituição da sociedade técnico-mecânica pela sociedade informatizada. Segue-se, em concomitância, o esgotamento da modernidade política, que se estruturou a partir do sistema de representação política. Com efeito, o espaço público deixou de ser exclusivo da organização partidária e torna-se, cada vez mais, constituído de uma multiplicidade de ações dos movimentos micrológicos, dentre outros, o movimento feminista, LGBT e ecológico. Ao mesmo tempo em que emerge, no interior dos limites territoriais dos países, grupos dos mais diversos interesses, verifica-se uma redução da soberania dos Estados-nações que sofrem múltiplas influências dos organismos internacionais e das empresas transnacionais.

Neste cenário, em que a crise de governabilidade é uma realidade que alcança tanto os países ricos como os subdesenvolvidos e abrange um amplo espectro ideológico, o modelo weberiano de dominação racional legal se apresenta como referência teórica exemplar para a caracterização da legitimidade política do Estado atualmente, pois se trata de uma teoria que originalmente concebe a legitimidade como fenômeno que se realiza no exercício das ações estatais e dos agentes públicos em conformidade com o ordenamento vigente; além disso, é uma abordagem que releva a ética da responsabilidade como fator de mensuração da legitimidade do poder político.

É certo que estão ocorrendo mudanças substanciais na estrutura econômica; mas, justamente porque Max Weber considera que a atividade econômica desempenha um papel decisivo na estruturação da rede de interação das formações sociais, influindo de maneira coercitiva em sua trajetória, faz-se mister retomar a dominação racional legal para a compreensão da legitimidade política no mundo atual. Outrossim, Max Weber trouxe para o debate acadêmico a existência da relação entre Estado, legitimidade e legalidade; portanto, ao se privilegiar o pensamento weberiano, está se estribando numa abordagem que, independente do contexto histórico, deve ser considerada em todas as análises que intencionam compreender a instituição do poder político.

\section{Legitimidade, conformidade ao direito e responsabilidade política}

A ideia da existência de uma autoridade legítima é o fator que funciona como balizador dos indivíduos no desenvolvimento de suas ações, portanto, trata-se do elemento que formata as maneiras como as pessoas se conduzem nas relações sociais. É a constatação empírica de que o comportamento das pessoas se orienta por uma autoridade específica o que torna a autoridade efetivamente válida. Weber (2002) esclarece que a "validação" de uma autoridade se inscreve num processo que extrapola as ações que são cometidas regularmente pelos indivíduos visando tão somente à reprodução de um costume ou de um interesse particular.

O sociólogo alemão demonstra sua afirmação com o seguinte exemplo, os transportadores de móveis, ao promoverem a divulgação de seus serviços na época de fins de alugueis, têm suas ações motivadas por interesse próprio; enquanto o servidor que comparece ao seu posto de trabalho no mesmo horário durante todos os dias úteis, bem mais que seguir um costume ou agir por interesse 
próprio, ele deve estar orientando seu comportamento por uma ordem normativa; entretanto, em sendo possível o livre arbítrio e a transgressão às normas estatuídas, este comportamento revela um agir baseado num "sentido do dever", num valor absoluto.

Vê-se no exemplo do comportamento do servidor a constatação da obediência em relação a uma autoridade. Pode-se afirmar, então, que são as premissas aceitas como verdadeiras que atribuem o caráter de determinação imperativa ao seu conteúdo, e por isto substanciam a relação social. Neste sentido, a validade da autoridade se dá quando o indivíduo reconhece que as obrigações emanadas das premissas se constituem num modelo digno de ser reproduzido (WEBER, 2002).

Deriva-se destes prolegômenos que o poder é condicionado à constatação de que ocorre obediência a uma autoridade. Como define Weber (2015/a), o que dá sentido ao poder é a probabilidade de imposição de vontade própria numa relação social. Assim, compreende-se a dominação como sendo a probabilidade de que uma ordem de conteúdo específico encontre obediência, enquanto a recorrência desta obediência, reproduzida de forma automática por uma pluralidade de pessoas, emprega sentido à disciplina. Para tanto, é preciso que exista a crença de que a potência do poder é real, e que, em função desta necessidade, para sua existência e fortalecimento, deva se tornar efetiva quando sua autoridade é questionada.

Para Weber (2015/a), a associação política, essencialmente uma associação de dominação, tem como característica fundante a vigência de suas ordens circunscritas a um território específico, ordens estas garantidas mediante ameaça ou adoção de coação física por um quadro administrativo. A delimitação de um território sobre o qual a associação política exerce o seu domínio, como explica Freund (2006), ao discutir a construção do sentido de interior e exterior, é o que dá consistência a definição da atividade política, uma vez que as ações dos membros que constituem a sociedade presente no interior do território é condicionada pela autoridade do grupo encarregado de fazer a ordem valer. Demonstra-se, com este entendimento, que o domínio é a essência da política, portanto, como visto na afirmação de Max Weber, a dominação é o que funda a associação política.

Ao referenciar o Estado como expressão moderna da associação política, Weber (2015/a) explicita que este ente deve ser compreendido como sendo uma empresa com caráter de instituição política; noutros termos, que tem como elemento base de sua constituição um quadro administrativo que reivindica e detém o "monopólio legítimo" da coação física com o fim de fazer valer as ordens vigentes. Em suma, Weber (2008) afirma que o Estado se constitui numa relação de homens dominando homens com base na violência considerada legítima, ressalvando-se que a coação física não se trata do meio administrativo exclusivo e nem o normal, sendo, na verdade, a última ratio. Weber (2015/a, p. 35) ainda acrescenta a sua precisão conceitual, que é da natureza do Estado, o fato de que só se pode falar de "coação física legítima quando a ordem estatal a permite ou prescreve".

Numa palavra, a dominação se dá em virtude da legalidade, ou seja, na combinação da existência de uma crença na validade do estatuto legal e da competência funcional, que se assenta em regras racionalmente elaboradas. Tais condições conduzem a formação de uma expectativa de que ocorra obediência no cumprimento das observações estatutárias. Mais especificamente, como esclarece Weber (2008, p. 56), este é o tipo de “domínio exercido pelo moderno 'servidor do Estado' e por todos os portadores do poder que, sob esse aspecto, a ele se assemelha." 
Duran (2009) esclarece que Weber trouxe o conceito de legitimidade para o estatuto de "problema central" no estudo da comunidade política, o que tornou obrigatória a adoção do pensamento deste sociólogo quando se busca refletir acerca do exercício do poder e de suas consequências. Com efeito, este procedimento introduziu uma variável que conduziu o olhar científico sobre o Estado para um tipo de abordagem que confrontou a forma centralizada eminentemente no direito positivo. Em suma, Weber tornou a categoria da legitimidade em questão fundamental para a compreensão da lógica de funcionamento do Estado e do exercício da dominação.

A modernidade na esquematização de Weber, como descreve Freund (2006), alicerça-se na reciprocidade funcional que se realiza entre Estado, direito e burocracia. O desempenho de cargos especializados e a operação do direito racional constituem a essência do Estado moderno. Isto ocorre porque estes dois fatores legaram um direito previsível e uma administração formalizada em cargos definidos, hierarquia funcional e regras delimitadas. Estes elementos se imiscuem e sustentam uns aos outros; uma vez que a crença na legitimidade do Estado decorre do fato de que suas ações são conformes e realizam-se no direito, por sua vez, o direito é factível no Estado. Outrossim, de um lado, a eficácia da burocracia formal é condicionada à existência de um sistema jurídico coerente, e, por outro lado, os instrumentos pertinentes à administração racional são funcionais à sistematização do direito. (DURAN, 2009)

Têm-se aí os elementos caracterizadores da dominação "legal-racional", que se alicerça na instituição do direito e do Estado, sendo que esta última tem a pretensão de ser a fonte única de legitimidade e, por isto, como visto anteriormente, pressupõe a detenção do monopólio da coerção. A força enquanto exclusividade do Estado é o mecanismo que conduz ao respeito do direito, instituído pelo próprio Estado, e que lhe dá legitimidade para realizar o constrangimento físico quando necessário.

No pensamento weberiano, a crença na legalidade da regra emerge como variável fundamental para a construção da legitimidade da dominação. Neste sentido, como princípio, a regra deve ser geral, concebida em vista a um fim determinado e de acordo com critérios formais. Mas, pode-se ainda definir a racionalidade jurídica moderna como a forma de interpretação normativa que empresta cientificidade às proposições legislativas. Com base nestes postulados, Duran (2009) afirma que o direito ocidental é constituído de um elevado grau de sistematização lógica e de uma racionalização dedutiva. Estes dois fatores são responsáveis pela formalização da legitimidade, uma vez que o direito racional se legitima no princípio da legalidade e da regularidade procedimental.

Ademais, no cerne do pensamento de Weber, a legitimação deve ser pensada concomitantemente à organização, pois a dominação visa objetivamente a alcançar um direcionamento. O sociólogo apreendeu que a dominação se expressa como administração em funcionamento. Em suma, encontra-se, em todas as formas de dominação, uma direção administrativa e, consequentemente, o exercício de ações visando à imposição de ordens sobre o constrangido. Com efeito, trata-se de uma necessidade do domínio organizado a existência contínua da administração, ou seja, é preciso um condicionamento da conduta dos indivíduos para com aqueles que pretendem ser os portadores do poder legítimo (WEBER, 2008).

Por isto, a legitimidade vai se estruturando enquanto aparelho de poder que, na sua operação, lhe proporciona fortalecimento. Também, faz-se mister a obediência dos seus membros e o 
desempenho de seus estratos hierárquicos superiores que jogam papel importante no processo de legitimação e deslegitimação do poder. Em suma, como sintetiza Duran (2009), para a dominação legítima do Estado, o que é essencial é a crença na legitimidade dos membros dos órgãos das instituições estatais nas quais se desenvolvem o processo de legitimação. Neste sentido, o Estado no curso de seu domínio também controla os bens materiais necessários para o exercício da violência, que o conduz obrigatoriamente a exercer um domínio sobre o quadro de pessoal e deter a propriedade dos materiais necessários à administração (WEBER, 2008).

Esta proposição weberiana de legitimidade é ainda hoje significativa, principalmente quando se considera que a secularização transcorrida na trajetória da modernização impede que valores se imponham imperiosamente sobre a maioria dos indivíduos, pois se assiste a uma ampliação da concorrência de valores. Esta impossibilidade de vontade comum derivada de um conjunto de consensos morais faz que as regras formais se tornem modelares às relações sociais. Por isto, os sistemas de regras formais se apresentam, atualmente, como adequados à orientação de comportamentos.

O poder político nas sociedades modernas aparece no pensamento weberiano como uma atividade de formulação e de realização dos fins. Entende ainda o sociólogo alemão que a concepção de responsabilidade, para além das realizações, deve ser compreendida como uma variável que é fortemente vinculada às consequências resultantes das ações empreendidas. Como salienta Duran (2009), Weber trouxe as consequências para o seio da política e atribuiu-lhe o estatuto de instrumento de mensuração da responsabilidade dos homens políticos. E não se pode negar que as consequências possibilitam avaliar, de forma abalizada, a contribuição dos homens políticos para a resolução dos problemas da comunidade.

A diferenciação econômica e os interesses daí decorrentes foram o que deram sentido à edificação das funções do Estado tal como passou a se conhecer modernamente. Com efeito, é caracteristicamente moderna a comunidade política com uma abrangência de funções que abarcam a produção legislativa, o exercício da proteção pessoal e da segurança pública, a vigilância e a proteção dos direitos vigentes, o fomento de atividades destinadas ao desenvolvimento das condições de sobrevivência e a proteção contra a ameaça de outras comunidades políticas. Nas reflexões weberianas acerca do nascimento do Estado racional, resta esclarecido que a associação do Estado com a jurisprudência formal favoreceu o florescimento e à consolidação do capitalismo (WEBER, 2006).

Outrossim, a ideia de política econômica estatal é uma característica que remete à Época Moderna, chegou-se a sua forma mais acabada com o advento do sistema mercantilista. Entrementes, trata-se de um fenômeno resultante de um processo histórico consoante a um encadeamento de eventos que redundaram na racionalização do direito e na formalização do processo jurídico. $\mathrm{O}$ processo de constituição da política econômica estatal, como chama a atenção Weber (2015/b, p. 520), apoia-se na existência de duas coisas que estavam espalhadas por vários lugares: "a política fiscal e a política de bem-estar, e esta última no sentido de garantir, na medida habitual, o sustento."

Neste sentido, a comunidade política se constitui, atualmente, no lugar, por excelência, em que se pode avaliar a relação entre convicção e consequência, relação que possibilita delimitar a natureza da responsabilidade. Isto porque são os interesses que emergem no seio das relações sociais que permitem proceder uma avaliação das consequências da ação estatal. Esta proposição weberiana, lembra Duran (2009), é o que define a comunidade política como uma realidade his- 
tórica e confere à responsabilidade uma dimensão, simultaneamente, empírica e prospectiva. A comunidade constitui-se, assim, na base sobre a qual se origina a ética da responsabilidade, pois é o lugar que inspira a racionalidade da escolha política.

Vê-se, então, que a ética da responsabilidade se delineia tanto na ética da convicção quanto na realidade empírica da comunidade. Ao se considerar a relação entre a convicção e as consequências das ações, tem-se que a racionalidade não se reduz a uma racionalidade meramente instrumental. Duran (2009) assevera que a referência prioritária dos resultados não se trata estritamente de uma racionalidade de tipo utilitarista; uma vez que, primeiramente, manifesta-se a racionalidade do homem público que alicerça sua ação a partir dos interesses da comunidade e a realiza tendo como parâmetro o contexto histórico. Eis os elementos que levam a definição da política como $a$ arte do possivel.

A ação do político é prospectiva, pois está assentada na responsabilidade relativa ao futuro. Assim, a luta para estar à frente da operacionalização do fazer político visa a influir na construção do futuro, por isto o indivíduo que atua no campo político deve prestar contas tanto pelo que faz quanto pelo futuro que corrobora para construir. Certamente, alguns políticos entram no jogo político tão somente porque aspiram ao poder, pois tencionam usufruir do prestígio daí advindo, o que caracteriza o exercício do poder movido para alcançar um fim que se encontra nele mesmo.

Saint-Pierre (1999), ao interpretar a sociologia política weberiana, assevera que o verdadeiro político jamais busca o poder como um fim em si mesmo, pois busca conquistá-lo no intuito de angariar os meios que tornam possível fazer valer os valores que orientam suas ações, como relações sociais justas, distribuição equitativa dos bens culturais e materiais, bem-estar coletivo, respeito à lógica do livre-cambismo etc. Neste sentido, a noção de valor está sempre presente na ação política como normatizadora, o que lhe atribui coerência interna da ação e do encadeamento de ações, tencionando alcançar as metas e os objetivos determinados.

Como o domínio do Estado moderno se dá por intermédio do funcionamento da administração, o funcionário que operacionaliza os meios necessários para alcançar os fins determinados é o agente que assegura a dominação. Neste sentido, vale distinguir os papéis do homem político do funcionário especializado, ou seja, daquele que faz as escolhas dos interesses a serem enfrentados, que propõe as diretrizes e define as metas a serem alcançadas, daquele que executa as ordens concernentes aos limites do cargo, portanto, distinguir as responsabilidades e, por conseguinte, as consequências das ações do burocrata e do dirigente.

Ao burocrata não cabe fazer política, pois sua responsabilidade é executar imparcialmente as ordens do mandante. Neste sentido, este funcionário repousa sua honra na execução de uma ordem como se correspondesse a sua convicção, mesmo quando tal ordem lhe pareça equivocada. Por sua vez, "a honra do estadista dirigente, consiste, pelo contrário, na exclusiva responsabilidade pessoal por aquilo que faz, responsabilidade que nem lhe é possível ou permitido recusar ou delegar." (WEBER, 2014, p. 416). A ação do burocrata é limitada, enquanto a do líder político é histórica, pois está investido da responsabilidade de projetar e estruturar o futuro do Estado.

A expectativa quanto à ação do político dirigente é que atue à frente do poder tencionando concretizar um "estado de coisas" desejado, que se pressupõe esteja mentalmente prefigurado como objetivo a ser alcançado, portanto, delineado como causa de sua ação. Saint-Pierre (1999) 
pontilha que entre a concepção dos fins desejados e os desdobramentos de ações concebidas como necessárias encontram-se toda uma sorte de consequências diretas e laterais. Isto exige uma racionalização do estado de coisas atual e dos meios pressupostos como os adequados para se chegar ao estado de coisas final. Neste sentido, faz-se necessário, sabendo ser impossível elencar todas as variáveis intervenientes, a construção de um modelo ideal de desenvolvimento, o que daria sustentação à normatização calculada da ação e às estimativas de consequências.

Salienta ainda Saint-Pierre (1999) que, para Max Weber, a "previsão inteligente" é fator imprescindível para a caracterização do ator político responsável, ou seja, o homem político que se orienta normativamente pela ética da responsabilidade, que mensura as consequências previsíveis de sua ação, ao antecipar seus desdobramentos e os encadeamentos que constroem um fluxo continuo, assim formando uma cadeia causal direcionada para a realização do fim originalmente concebido.

Em suma, a reflexão weberiana possibilita a percepção analítica da legitimidade política como sendo constituída de dois níveis. A legitimidade do tipo ideal, que se trata do nível procedimental, que baliza a ação dos poderes públicos e modela as condições de seu desenvolvimento, ou seja, a conformidade ao direito e o respeito aos procedimentos. É esta legitimidade que define o paradigma da intervenção e, por consequência, a natureza do regime político. A ação propriamente política, que se trata do nível de responsabilidade política, articula os fins escolhidos, os objetivos determinados e as consequências a serem perseguidas. É a responsabilidade política que permite alcançar os resultados que conduzem aos objetivos delineados; sendo, por isto, a responsabilidade o que legitima a ação. (DURAN, 2009)

Nesta classificação, encontram-se os elementos que substanciam e justificam o poder. E também permite vislumbrar que o pensamento weberiano alicerça a legitimidade na constatação empírica da crença na validade do direito, observada na obediência de todos as normas vigentes, inclusive, pelas autoridades (CHAZEL, 2009). Têm-se neste processo a constatação de que é assaz frágil e subjetivo o caráter da legitimidade. Isto decorre, como mostra Max Weber, porque é uma probabilidade real o antagonismo entre legalidade e legitimidade, uma vez que somente a legalidade é incapaz de dotar o poder político de legitimidade.

\section{A mutação das fontes de reconhecimento do poder do Estado}

Na perspectiva do Estado, como explica Duran (2009), o poder é legítimo quando efetivamente controla e enquadra indivíduos ou grupos. É possível afirmar, então, que a legitimidade estatal decorre da certeza de que a não submissão às formas de controle implicam em consequências mensuráveis em relação ao grau de desobediência à autoridade impositiva. Conclui o autor, então, que tais princípios conduzem à compreensão de que o poder político se trata de poder sobre bem mais do que poder de. Entretanto, a despeito deste amplo entendimento, não se pode deixar de reconhecer que o poder encontra sua justificativa também nas suas realizações.

Os consensos concernentes às ações do Estado, no transcurso da trajetória da modernização, que abrange o período relativo a fins do século XIX até meados do século XX, tornaram-se também objeto de mensuração do poder estatal. Deu-se aí a instituição do Estado de Seguridade Social, uma 
forma de governo que se consolidou após a Segunda Grande Guerra e tem como alicerce um amplo entendimento que formatou uma tríade baseada na organização dos trabalhadores, dos empresários e do Estado. Este modelo de organização política funcionou para assegurar a administração da ampliação da produtividade e de sua equitativa distribuição. Para tanto, como explicita Lipietz (1991), inaugurou-se uma regulação assentada numa legislação social asseguradora de ganhos salariais compatíveis ao crescimento da produtividade nacional, bem como viabilizadora de um sistema previdenciário capaz de assegurar a dignidade dos trabalhadores impedidos de uma vida digna, em função de desemprego, doenças, envelhecimento, etc.

Com efeito, a legitimidade das autoridades públicas passou a ser condicionada à percepção do cidadão quanto à eficácia das políticas estatais. Isto ocorreu porque a instituição de doutrinas jurídicos-políticas reguladoras do Estado alicerçadas no princípio da igualdade, por intermédio da universalização de direitos viabilizadores do bem-estar social coletivo, conduziu o poder político a uma dimensão que, para além de imprimir a obediência a regras orientadoras de ações legitimadas via consenso coletivo, passou a incorporar a capacidade de atender às demandas de ações direcionadas para a solução dos problemas que afetam os segmentos populacionais e dão substância a opinião pública (DURAN, 2009).

Neste sentido, as políticas públicas se constituíram no cerne da disputa pela conquista e manutenção do poder político. Outrossim, o jogo político vem se consolidando cada vez mais como disputa de proposições de ações estatais, elaboradas no intuito de atender aos interesses emergidos nas relações sociais, bem como uma disputa de resultados alcançados, que são avaliadas pelos indivíduos ao mensurarem os impactos das ações do Estado em suas vidas cotidianas. Como explica Duran (2009), a política que, desde sempre, se trata da adoção de estratégias de dominação postas em jogo na relação de forças em disputa pelo poder, tornou-se, precipuamente, uma atividade de grupos de interesses que entabulam mecanismos de mobilização de recursos, definição e hierarquização de metas coletivas e elaboração e execução de políticas públicas visando a alcançar tais metas delimitadas.

Esta mudança na hierarquização de objetos norteadores do fazer político se alterou, de acordo com King (1988), devido à construção dos pilares que dão sustentação ao Estado de bem-estar, que se enraizaram à estrutura social e política das sociedades industriais, de sorte que resistem fortemente às investidas dos ideais neoliberais. As mudanças nos padrões de emprego, em virtude da economia política adotada pós 1945, em que se verificou alterações nas fontes de renda, principalmente devido à ampliação da dimensão do setor público, ocasionou uma notável inflexão no conteúdo das atividades políticas, que se concentrou mais fortemente no desenvolvimento de rotinas direcionadas para a assistência social, o bem-estar público e a educação pública. Isto mudou a cultura política a partir da inserção e participação estrutural do Estado de bem-estar nas democracias ocidentais. Tornou-se forte a influência da classe média beneficiária dos serviços estatais e do apoio às atividades empreendedoras, produtoras de mercadorias e serviços de pequeno e médio porte.

Os marcos delineadores do Estado de bem-estar sofreram profundas alterações após a Segunda Grande Guerra. As ideias de Léon Bourgeois (2017), considerado um de seus primeiros expoentes teóricos, com a publicação da obra Solidarité, em 1896, sustentaram a proposição de uma doutrina jurídico-política situada entre o individualismo liberal e o socialismo revolucionário. Encontram-se 
no pensamento de Bourgeois os alicerces que fundaram o Estado de bem-estar na primeira metade do século XX, em que sobressaem políticas direcionadas à universalização do ensino básico e para a criação de assistência social estatal aos impedidos de assegurar sua própria subsistência.

Para Amiel (2009), Bourgeois desenvolveu um conceito de solidariedade baseado no princípio da existência de uma dívida de prestação de serviços de uma geração para com as gerações precedentes, que legaram toda uma gama de bens materiais e imateriais. No interior deste processo, deriva-se uma obrigação do indivíduo com seus contemporâneos e da coletividade em relação às gerações seguintes, donde se origina um quase-contrato, que viabiliza o desenvolvimento permanente dos indivíduos e da coletividade com base numa solidariedade que interliga gerações sucessivas num encadeamento de benefícios herdados e obrigações previamente assumidas.

Entretanto, as experiências concretas de governança assentadas na ideia do Estado mais presente na regulação das relações sociais consagraram, primeiramente, os direitos civis; porém, como esclarece Marshall (1967), os seus efeitos se mostraram constrangidos por longo período, em virtude do preconceito de classe e da falta de oportunidade de trabalho. Em segundo lugar, as ações estatais possibilitaram a consolidação dos direitos políticos, que instituíram poder potencial, mas, como demandavam experiência e organização para o seu exercício, o que se verificou foi um direito inicialmente restrito e que foi paulatinamente se alargando, dada a necessidade de tempo para seu real desenvolvimento. Por último, os direitos sociais instituídos no período pré 1940 eram limitados, uma vez que buscavam diminuir a pobreza e não alterar verdadeiramente o padrão de desigualdade.

Destarte, foi após a Segunda Grande Guerra que o Estado de bem-estar passou de fato a universalizar direitos sociais, ao estabelecer e distribuir mais equitativamente serviços de saúde, educação e ampla assistência aos desempregados e idosos, além de instituir política de padrão mínimo de renda e de direito ao trabalho. A adoção desses instrumentos induziu, segundo King (1988), a mudança no papel do Estado e sua relação com a economia, o que provocou modificações nas causas e na natureza do conflito social, de tal maneira que as atividades governamentais passaram a se constituir quase exclusivamente em expressões ou respostas a demandas sociais.

A reflexão acerca dos princípios do Estado-providência, efetivada por Oliveira (1988), demonstra que este modelo de governo estabeleceu um novo padrão de financiamento público, quando foram aperfeiçoadas políticas anticíclicas lastreada na teoria do economista inglês John Maynard Keynes. Na obra Teoria Geral do Emprego, do Juro e do Dinheiro, originalmente publicado nos anos 1930, Keynes (1970) fundamenta que se faz necessária a organização de uma esfera pública de onde se originam diretrizes que dão sustentação, com base no fundo público, ao financiamento da acumulação do capital, simultaneamente, ao financiamento da reprodução da força de trabalho, que se estende para a população em geral via gastos sociais.

Com efeito, ações estatais sempre foram adotadas com o intuito de corroborar a reprodução do capital. Como chama a atenção Oliveira (1988), não teria ocorrido a própria formação do capitalismo sem que houvesse subsídios públicos. De fato, foram os recursos reais e imperiais associados aos dos banqueiros e dos mercadores que possibilitaram a expansão comercial no século XV e XVI, bem como a ocupação das terras descobertas, a dominação dos nativos e a exploração aí realizada. Por outro lado, o auxílio caritativo aos pobres, tendo a Igreja como protagonista, tam- 
bém contava com o auxílio de particulares e dos recursos públicos. Entretanto, com o Estado de bem-estar, inaugurou-se uma forma estável de financiamento que passou a dispensar o exercício da pressão de grupos específicos. Tal estabilidade adveio da garantia dos principais agentes sociais e políticos, acordes de pactos constitutivos de uma esfera pública institucionalmente regulada.

As mudanças pós 1940 atribuíram um novo caráter ao fundo público, como explica Oliveira (1988, p. 9), tornou-se "um ex-ante das condições de reprodução de cada capital particular e das condições de vida." No concernente à reprodução da força de trabalho, verificava-se, nos anos 1980, uma crescente importância do salário indireto, de tal maneira que, neste período, contribuía para a composição da renda domiciliar numa escala de 33\% a 45\%, entre os países membros da Organização para a Cooperação e Desenvolvimento Econômico (OCDE). Observa-se neste movimento uma socialização dos custos de reprodução da força de trabalho, que se desloca do custo de produção e passa a ser financiada pelos recursos públicos. O salário indireto constitui-se na base de sustentação do consumo de massa, alimentado com a formação de renda disponível a partir da liberação de parte do salário direto. Constituiu-se, assim, a criação das condições necessárias para dar sustentação à produção em massa de bens de consumo duráveis, que se estrutura nas despesas governamentais com serviços públicos e nos salários indiretos. Isto conduziu os fundos públicos a assumir o estatuto de elemento estrutural do capitalismo industrial (OLIVEIRA, 1988).

Com efeito, a gestão da ação pública assumiu o status de centralidade na legitimidade do poder do Estado, que está sujeita, contemporaneamente, a mudanças mais ou menos intensas de consensos delimitadores de demandas coletivas. As economias centrais experimentaram, do final da Segunda Grande Guerra até meados dos anos 1970, um período áureo, em que a lógica de funcionamento do Estado de bem-estar gerou uma combinação de aumento de lucros das empresas com universalização de direitos e melhorias das condições de vida dos trabalhadores.

Porém, como assevera Offe (1984), nos anos 1980, as altas taxas de desemprego e o amplo endividamento público colocaram sob suspeita esse modelo de governança. Teve início aí a crise que se abateu sobre a democracia capitalista, em que predomina uma desconfiança dos eleitores no sistema representativo como possibilidade de atender as múltiplas demandas dos cidadãos. Claus Offe indica que, a partir daí, inaugurou-se uma ingovernabilidade que passou a se abater sobre vários Estados-nações, que se erige na incapacidade da luta política em atender interesses antagônicos da reprodução do trabalho e do capital.

Por outro lado, como salienta Habermas (1997), o sistema político é, hoje, um centro poliárquico, em que sua constituição se dá por intermédio de uma multiplicidade institucional, que abrange os mais diversos órgãos da administração pública, o judiciário, os institutos e fóruns de formação democrática de opinião e de vontade, como as assembleias parlamentares, eleições políticas, sindicatos etc. Além desses atores infranacionais, segundo Duran (2009), constituem também essa poliarquia atores supranacionais, formados pelos organismos internacionais, como a Organização das Nações Unidas (ONU), e os de controle comercial e financeiros, como a Organização Mundial do Comércio (OMC) e o Fundo Monetário Internacional (FMI).

Este cenário implica no fato de que as demandas sociais formuladas a partir das lutas de interesses de forças internas à estrutura social devem ser observadas num espectro mais amplo, uma vez que o Estado-nação não detém atualmente o monopólio dos instrumentos que têm reflexo di- 
reto na legitimidade de seu poder. Furtado (1999), ao discutir os fatores intervenientes às políticas de desenvolvimento dos países periféricos e semiperiféricos, afirma que sempre se fez necessário considerar, quando da elaboração do modelo de desenvolvimento, conjuntamente, as peculiaridades internas e os constrangimentos dos quadros internacionais. Após a crise que se abateu sobre as economias centrais, assentadas no Estado de bem-estar, passou-se a assistir, por exemplo, na América Latina, à adoção acrítica de políticas econômicas benéficas às empresas transnacionais, ou seja, os atores nacionais são preteridos em seus interesses diante da força política que representa localmente os interesses das empresas transnacionais.

Para Calliot-Thélene (2012), os Estados hoje estão confrontados com poderes que se lhe opõem e que são edificados fora de suas fronteiras nacionais, tendo o sistema da economia mundial como locus produtor desses poderes. A mundialização é aqui entendida como possuindo uma abrangência que contempla aspectos demográficos (as migrações), jurídicos (a constituição de instâncias judiciais internacionais) e políticos (a limitação da soberania dos Estados).

A modernidade complexa, permeada de contradições multifacetadas, explicita a insuficiência da atividade eleitoral como elemento fundante da democracia. Arruda (2010), alicerçado no conceito de sociedade de risco, construído, dentre outros por Beck, Giddens e Lash (1997), Hespanha (2002) e Hall (2006), defende que as transformações das instituições, em suas formas e funcionamentos, com imperiosa implicações na construção da identidade cultural, estão diversificando os padrões orientadores dos comportamentos das pessoas, das organizações produtivas e dos Estadosnações. Especificamente, as pessoas estão se tornando cada vez mais autônomas para decidir acerca de sua trajetória de vida, portanto, definir e hierarquizar os valores que balizam seu modo de agir, pensar e sentir. A emergência deste novo padrão civilizatório demanda para seu entendimento que se ponha no mesmo plano de análise as dimensões econômica, cultural e política, uma vez que estas múltiplas referências comportamentais se dão, grosso modo, a partir de influências difusas oriundas de diferentes dimensões da estrutura social global.

Arruda (2010) define situação de risco como a possibilidade, em função das mudanças e das indefinições no padrão de ordenamento das instituições, de que indivíduo esteja mais centrado em si mesmo do que nos outros ao delinear sua biografia. Tal situação foi se constituindo a partir das mudanças no seio da própria modernidade que a conduziram de uma lógica de funcionamento simples para uma lógica bem mais complexa. No campo econômico, tem-se que as organizações burocráticas privadas, após a Segunda Grande Guerra, consolidaram uma produção com planejamento de médio e longo prazo, assentada no trabalho simples e rotineiro, com grande estoque de matérias-primas, visando à produção em larga escala no sentido de atender um mercado massivo. A estagflação (estagnação da produção associada ao aumento dos preços das mercadorias) econômica provocada pela crise de petróleo, nos anos 1970, deu origem a um movimento de renovação tecnológica e organizacional, nas duas décadas posteriores, que alteraram substancialmente a lógica de produção das empresas capitalistas de grande porte, levando-as a substituir o modelo de produção rígido por um modelo flexível. Este modelo passou a ser orientado por um planejamento de curtíssimo prazo, aumentando significativamente a velocidade das mudanças tecnológicas, das características das mercadorias produzidas, extinguindo e fazendo surgir novas mercadorias, alterando e criando novas tarefas e ocupações na produção, requerendo novas habilidade e conhecimentos dos trabalhadores. 
Tais mudanças no interior das modernas empresas capitalistas decorreram numa contínua transformação dos padrões orientadores das empresas, em sua concorrência capitalista, das pessoas, em sua adequabilidade ao mundo produtivo e, por conseguinte, do Estado, na formulação de políticas necessárias às novas demandas dos atores sociais. Arruda (2010, p. 501) aponta que se verificaram abalos em questões basilares da sociedade moderna, como: "O que define uma empresa competitiva? Quais os requisitos e as competências necessárias ao trabalhador? Onde alocar os recursos públicos para promover uma regulação do desenvolvimento?” Enfim, verificou-se uma ruptura nos padrões do capitalismo que abalou as estruturas já consolidadas, e com isso inaugurou-se uma sociabilidade em que a incerteza presente nos mercados, nas empresas, alcançou a dimensão cultural e o sistema político.

Se, de um lado, a mudança no padrão tecnológico permitiu a inserção avassaladora da mulher no mercado de trabalho, de outro lado, erodiu as bases fundamentais da família patriarcal. No entendimento de Beck, Giddens e Lash (1997), está em xeque um dos pilares fundamentais da sociedade industrial, ou seja, as classes sociais que se constituem com base na soma das famílias nucleares, que fundou a divisão do trabalho a partir da definição dos papéis sociais dos homens e das mulheres. $\mathrm{O}$ fato de homens e mulheres poderem optar por um estilo de vida contrário ao que está inscrito na tradição torna-os produtores da própria trajetória de vida e em iconoclastas da moral vigente. Simultaneamente, o avanço tecnológico na comunicação contribui para a tessitura de uma rede de relações virtuais, e também corrobora para a construção de ações corruptoras dos padrões instituídos na sociedade industrial. Para Giddens (2001), as mudanças verificadas no final do século XX deram início a uma "destradicionalização" que, iniciada como resultado da expansão dos mercados, plasmou-se por toda a sociedade arrastando os indivíduos e as instituições para um permanente estado de crise.

Estas transformações conduzem Arruda (2010, p. 504) a concluir que o que mais reflete "a crise atualmente vivida na democracia capitalista seja a desconfiança dos eleitores no sistema representativo. A representação política é hoje questionada quanto a sua legitimidade na defesa dos interesses dos cidadãos.” Enfim, a nova base técnico-científica da produção econômica e os seus reflexos transformadores no campo moral fizeram emergir um indivíduo não mais submisso aos constrangimentos dos laços consanguíneos, iconoclasta dos valores característicos da sociedade industrial, que se encontra diante de múltiplas possibilidades de decisões para o enfrentamento dos problemas cotidianos, que têm diante de si questões locais e nacionais que reclamam sua participação (ELIAS, 1994). Ou seja, os indivíduos cada vez mais escapam da proibição da ambiguidade e colocam-se no mundo como sujeitos ambivalentes, que não mais se enquadram tão facilmente nas definições clássicas de pensamento político de direita ou de esquerda, tornando-se de difícil representação política institucional, dada a multiplicidade de valores e interesses que hoje cada pessoa porta em si.

É primordial, então, como defende Duran (2009), pensar a participação de todos os implicados nas consequências das ações públicas, participação esta que se estende desde a definição de seus propósitos até o controle de suas execuções. No cerne desta ideia, está pressuposta a superação do poder político limitado ao exercício do governo exclusivamente baseado na legalidade, ou seja, na consideração de que a conformidade dos comportamentos ao direito é a fonte exclusiva de legitimidade. 


\section{O pensamento weberiano e a legitimidade do Estado contemporâneo}

É inequívoco, no pensamento weberiano, como demonstrado anteriormente, que a estrutura da dominação e o seu desenvolvimento conduz a ação social a constituir o sentido da relação social, assim trata-se do elemento que impulsiona as pessoas a perseguirem de forma associada um determinado objetivo. Mais precisamente, as ações sociais que formatam relações associativas do tipo racional resultam na instituição da dominação burocrática. A dominação exerceu e continua a exercer papel fundamental nas formações socioeconômicas, como se observou no regime feudal e observa-se na moderna empresa capitalista, uma vez que se encontram aí os fundamentos que possibilitam a concepção coletiva dos objetivos, das estratégias e dos meios para alcançá-los.

Com efeito, não é exagero imaginar que se encontra, num horizonte extremamente longínquo, a existência de relações sociais marcadas pela dominação, até porque ela se manifesta principalmente na forma de administração (WEBER, 2015/b), sendo difícil idealizar a existência de associações de pessoas objetivando a qualquer fim em que não haja um mínimo de hierarquia, um poder de um ou de uns sobre outro ou outros. Porém, resta claro que vivenciamos, atualmente, mudanças significativas no campo econômico, moral e político, com implicações imperiosas no interior e no exterior das formações sociais, o que demanda novas formas e funcionamentos das organizações estatais, da burocracia.

Em sua forma mais próxima do ideal tipo, foi somente no capitalismo avançado que se instituiu a dominação da economia privada, com a existência da empresa burocrática; e, somente com o advento do Estado moderno, emergiu a dominação baseada no direito público concretizada na autoridade burocrática. Weber (2015/b) discrimina os princípios instituidores da natureza da dominação burocrática, em primeiro lugar, assentada no funcionalismo moderno, onde prepondera a distribuição fixa das atividades normatizadas objetivando a realização dos fins do complexo burocrático, com poderes e comandos dos meios de coerção regulamentados, e quadro de pessoal compatível às racionalizações das funções necessárias ao seu funcionamento. Segue-se na explicação weberiana, concernente aos elementos essenciais da burocracia, a existência, nas organizações estatais, religiosas, empresas capitalistas partidos políticos e organizações de todos os tipos, de sistemas fixamente ordenado de mando e subordinação de autoridades, em que os que se encontram no exercício de cargos inferiores são fiscalizados pelos superiores, que formatam uma sequência de instância hierárquica.

Esses elementos aqui sumariamente descritos conduziram a organização burocrática a se tonar o modelo ideal de associação da modernidade, além disso, a burocracia constituiu-se, na verdade, em fator estrutural da lógica de funcionamento da sociedade moderna. Isto se derivou do fato de que, com a burocracia, desenvolveu-se um tipo de organização que, na sua forma ideal, prima pela "precisão, rapidez, continuidade, discrição, uniformidade, subordinação rigorosa, diminuição de atritos e de custos materiais e pessoais." (WEBER, 2015/b, p. 212). Tais consequências do funcionamento da burocracia são perfeitamente adequadas às exigências da economia capitalista moderna, principalmente quando se toma como referência a empresa de grande porte atuante em mercados competitivos.

$\mathrm{Na}$ perspectiva do funcionamento do Estado, a cultura técnico-científica que se plasmou por toda a formação social moderna, em que se busca alcançar a execução das tarefas de maneira 
coordenada para se atingir o máximo de precisão e uma continua melhoria da qualidade e aumento da quantidade, o que traz a objetividade para um primeiro plano e secundariza os desejos e os sentimentos individuais, tornou-se o elemento fundante do direito conceitualmente sistematizado e racional, em que predomina a associação de funções realizadas por especialistas que atuam objetivando a decisão assentada em princípios técnicos, portanto, o mais distante possível de influências de sentimentos e desejos particulares. Eis aí os fatores que levaram o direito ao afastamento da tradição, dos pressupostos irracionais e da influência personalista dos senhores, características do tipo de direito que foi predominante até o medievo, o que conduz a afirmação de que os fundamentos burocráticos foram paulatinamente fazendo a transição do direito antigo e medieval para o direito moderno.

Mas o Estado estruturalmente constituído nos princípios instituidores da burocracia, como está conceitualmente aqui delimitado, trata-se de uma formulação ideal tipo que só excepcionalmente encontra correspondência plena na realidade. Ao proceder a descrição do processo histórico que consolidou o direito moderno, Weber (2015/b, p. 215), por exemplo, esclarece que: "O país que primeiro alcançou na Época Moderna um capitalismo intensamente desenvolvido, a Inglaterra, conservou, por isso, uma justiça menos racional e menos burocrática." Com efeito, as influências da tradição nas relações das formações sociais contemporâneas ainda se fazem presentes, portanto, não é estranho que, mesmo nas sociedades capitalistas que se encontram num grau mais elevado de desenvolvimento, com um complexo sistema econômico assentado em interesses setoriais e geográficos múltiplos, que exige um quadro de decisões das organizações públicas e privadas assentada numa racionalidade conceitual, sejam frequentes as influências do personalismo e do sentimento.

Entrementes, o pensamento weberiano ressalta que não é de todo desejado que se impregne totalmente o direito da objetividade e do tecnicismo. Lembra Max Weber que é repudiada nas modernas sociedades industriais a figura do juiz autômato, que reproduz mecanicamente sentenças apoiadas literalmente na ordenação vigente. Ressalta ainda que as populações em condições de sobrevivência vulnerável, não são beneficiárias da "igualdade jurídica" formal e nem da aplicação "calculável" do direito, que em muito satisfaz os interesses dos mais abastados. Para os primeiros, fazem-se necessários um direito e uma administração que os conduza à condição igualitária de oportunidades socioeconômicas, o que, invariavelmente, requer ação de caráter informal e orientação de sentido ético.

Para além da possibilidade de uma rigidez que torne as decisões inadequadas às transformações na totalidade social e ao surgimento de renovadas ou inovadoras demandas coletivas, Marcuse (1998) traz a ideia de que o próprio sucesso da razão burocrática porta em si irracionalidades destrutivas. No seu entendimento, o conceito weberiano de razão, que comporta a matematização progressiva da experiência e do conhecimento, abrangendo todas as ciências e mesmo a vida cotidiana, a existência do experimento e da prova racional como decisivo tanto para a ciência quanto para o "modo de vida", possibilitam a transição da razão teórica para a razão prática, que se consolida na organização constituída de funcionários instruídos para o exercício da especialização técnica. A ratio weberiana seria, então, capaz de racionalizar o impulso para ganho, inscrito no espírito humano, tornando-o impulso para o lucro, ou seja, para a obtenção de vantagens apoiado na racionalização do contexto e dos meios e com o objetivo de se projetar no futuro como na condição de permanente crescimento. 
Enfim, Max Weber descreve que, na história da civilização ocidental, o controle do impulso para o ganho conduziu a razão ocidental à razão econômica do capitalismo. Nas palavras de Marcuse (1998, p. 116), o pensamento weberiano descortina o fato de que "a racionalidade se torna condição de rentabilidade, por sua vez orientada por um cálculo sistemático, metódico, cálculo capitalista." Tem-se aí uma abstração da racionalidade derivada da realidade concreta que reduz qualidade em quantidade, ao transformá-la em eficiência funcional viabilizadora da dominação de todas as particularidades, de sorte que a razão abstrata se concretiza na dominação calculável da natureza e dos homens.

A razão, assim tornada razão técnica, trata-se de uma conceituação alicerçada na abstração quantificadora, ou seja, que abstrai todas as particularidades e torna possível a eficiência calculável no cerne do aparato capitalista. Mas, em sua crítica, Marcuse (1998), salienta os limites da razão técnica como propulsora de um desenvolvimento ad infinitum. O autor apresenta como um elemento que se volta contra a razão tal qual demonstrada por Weber, emergido no cerne da necessidade da acumulação de capital cada vez mais intensa, o processo de "obsolescência planejada", uma contra-razão ou irracionalidade metodologicamente desenhada enquanto necessidade social. De fato, fez-se necessária a inoculação do mecanismo de destruição produtiva no interior do processo de desenvolvimento das forças de produção. Destarte, a rentabilidade capitalista - a ratio ocidental - passou a ser assentado no cálculo do risco da destruição do próprio produto em face do risco da destruição causada por uma rentabilidade superior do concorrente.

A irracionalidade que no processo de racionalização capitalista tornou-se razão do desenvolvimento, para além do produto, alcança a natureza na promoção da ampliação da riqueza a ser gerada e disputada por cada vez mais amplas camadas da população. Esta razão impulsionadora das forças destrutivas, atualmente cerne da luta pela existência, "se aguça tanto no plano interno dos Estados nacionais como no plano internacional.” (MARCUSE, 1998, p. 119).

A despeito da crítica radical de Herbert Marcuse, na verdade, empiricamente verificável, Duran (2009) defende que as transformações históricas do exercício do poder não esgotaram o ideal tipo weberiano da dominação racional legal, uma vez que esta abordagem permite a consecução de comparações históricas capazes de fazer emergir, por contraste, as singularidades da ordem política contemporânea. Isto ocorre porque o modelo proposto por Weber possibilita a construção conceitual contextualizada, o que torna factível sua adoção visando à inteligibilidade das causalidades do presente.

Max Weber, de acordo com Duran (2009), percebeu, em sua época, a tendência para a justificação do poder político se localizar bem mais na performance estatal concernente ao atendimento das demandas coletivas. Justamente por isto, o sociólogo alemão trouxe a temática da responsabilidade política enquanto variável significativa para o entendimento da legitimidade do poder. Mais precisamente, as consequências da ação estatal se tratam tanto de medida da responsabilidade como de validação da legitimidade do poder. No pensamento weberiano, assevera-se que a obediência recorrente torna evidente empiricamente o reconhecimento de uma dominação, enquanto a mensuração positiva das consequências das ações do Estado valida o exercício do poder. Neste sentido, articula-se nesta abordagem teórica premissas que contemplam tanto o poder sobre como o poder de. 
A comunidade é salientada como referência onde se concretiza a legitimidade do poder, ou seja, o lugar onde se dá a qualificação da ação estatal. É certo que não estava dado para Weber a imprecisão que se tem hoje para localizar qual a comunidade ou comunidades que devam ser tomadas como referências para a mensuração das consequências da ação política. Isto se torna claro quando se trata das questões referentes aos direitos de terceira geração que extrapolam os limites territoriais do Estado-nação, pois concernem ao planeta como um todo. Sem dúvida, os Estados-nações são confrontados em sua soberania e na capacidade de decisões que atendam os interesses internos, o que suscita a questão de como pensar o poder político e sua legitimidade, ante a fragmentação de centros de decisões, atores e de espaços de referência política.

A sociologia política de Weber, apesar do fenômeno da globalização e das suas consequências para a limitação da soberania dos poderes do Estado nacional, de acordo com Calliot-Thélene (2012), ainda permite compreender as nuances da legitimidade do poder atualmente. Com efeito, os Estados nacionais ainda são os autores principais da produção de normas, mas é preciso considerar que o Estado territorial não é mais o espaço exclusivo da formulação do direito. Isto porque são cada vez mais influentes as organizações da sociedade civil que muitas vezes se estruturam e operam em escala mundial, assim comprometendo a soberania ilimitada ressaltada nas doutrinas clássicas

Para Calliot-Thélene (2012), as múltiplas manifestações da sociedade civil provocaram uma desterritorialização das "potências" ordenadoras das relações sociais. Os compromissos coletivos também se adaptam a este tipo de formulação mundial que extrapola os marcos nacionais. Os desequilíbrios ecológicos, o esgotamento das fontes de energia e o aquecimento global, consoante as consequências, como os fluxos migratórios, tornaram-se questões políticas globais fundamentais; por outro lado, os espaços de poder que podem atuar sobre estes problemas são extremamente diversos. Eis aí o limite que se coloca à proposta weberiana, mas que pode ser superado, e mesmo substanciar fortemente as reflexões sobre as questões políticas contemporâneas, uma vez que se trata de uma abordagem comparativa de amplas dimensões e com formidável acento posto na influência da economia capitalista, no que concerne à estruturação futura da sociedade moderna.

\section{Conclusão}

Como explicitado ao longo do texto, o fundamento para a existência de uma comunidade política é a associação de pessoas com interesses que extrapolam aqueles dirigidos para as atividades que objetivam fins meramente econômicos. Em suma, a sua constituição decorre da elaboração de ordens destinadas à regulamentação de uma multiplicidade de áreas de interesses coletivos. Alicerçado nesse entendimento, Max Weber compreende que o status das associações políticas está condicionado à crença de que as ações estatais objetivam atender demandas coletivas e se desenvolvem em conformidade à lei.

Entretanto, a complexificação da modernidade, com base no desenvolvimento econômico, implicou a ampliação de novos interesses e, consequentemente, demandas de garantias inovadoras, ou seja, da racionalização de ordens políticas visando a assegurar as ações viabilizadoras dos inumeráveis desejos dos membros da comunidade. Outrossim, o Estado permanece necessário para 
a realização dos interesses coletivos, mas os desafios advindos do próprio desenvolvimento da modernidade, que se recrudescem desde fins do século XX, reclamam uma racionalização capaz de uma adequabilidade das ações estatais às questões atuais. De todo modo, não se trata de que os fatores apontados por Max Weber como determinantes da legitimação do poder e da autoridade estatal não devam ser levados em consideração nas análises do Estado contemporâneo; entretanto, os contextos internos e externos aos Estados-nações, permeado de novas configurações advindas com o fenômeno da globalização, conduzem a necessidade de um alargamento do entendimento da dominação racional-legal.

Assiste-se, hoje, a uma mudança no cerne da produção capitalista, a indústria mecânica que cimentou o projeto da modernidade foi suplantada pelo serviço informatizado; a burocracia fundada na especialização, em trabalhos com atividades rotineiras, que redundou numa empresa produtora de mercadorias em larga escala, em reduzidas margens de erro e custos continuamente reduzidos, por sua vez, também foi superada. Esta lógica organizacional que se plasmou por todas as esferas da vida social, influindo nas expectativas dos membros das organizações políticas e no funcionamento dos poderes públicos, atualmente, se apresenta como um engessamento, posto que é inadequado ao funcionamento da burocracia empresarial.

Destarte, por um lado, Max Weber, defendia que é mister definir o Estado em suas características modernas, uma vez que o seu desenvolvimento decorre mesmo do processo instituidor da modernidade. Por outro lado, chamava a atenção para o fato de que o Estado moderno se assenta numa dimensão administrativa e numa dimensão jurídica, ambas não estáticas, pois podem sofrer alterações por intermédio de estatutos, que funcionam como norteadores da ação associativa que se dá via membros do quadro administrativo.

Pode-se asseverar que a crise de representatividade política e de legitimação do Estado é um reflexo das mudanças originadas na burocracia empresarial. Entretanto, a teoria weberiana da legitimidade é ainda factível; pois, como definido pelo próprio Weber, trata-se de um artifício metodológico que intenciona a edificação de marcos conceituais visando a fins precisos, não estando somente voltada à compreensão do passado, assim, constituindo-se numa contribuição que possibilita uma permanente refundação analítica da realidade.

\section{Referências}

AMIEL, Olivier. Le solidarisme, une doctrine juridique et politique française de Léon Bougeois à la Ve République. Parlement(s), Revue d'histoire politique, v. 11, n. 1, 2009, p. 149-160.

ARRUDA, Gerardo Clésio Maia. Identidade cultural e (des)politização na sociedade de risco. Revista Mal Estar e Subjetividade. v. 10, n. 2, jun/2010, p. 495-520.

BECK, Ulrich ; GIDDENS, Anthony; LASH Scott. Modernização reflexiva: política, tradição e estética na ordem social moderna. São Paulo: Editora da Universidade Estadual Paulista, 1997.

BOURGEOIS, Léon. Solidarité. Disponível em: http://www.uqac.ca/Classiques des sciences sociales. Acesso em: 10 out. 2017.

COLLIOT-THÉLENE, Catherine. De una modernidad política a otra. Los análisis weberianos de la política frente a la prueba de la mundialización. In: LÖWY, Michael. Max Weber y las paradojas de la modernidad. Buenos Aires : Nueva Visíon, 2012. 
DURAN, Patrice. Légitimité, droit et action publique. L'Année Sociologique. v. 59, n. 2, 2009, p. 303-344. ELIAS, Norbert. A sociedade dos indivíduos. Rio de Janeiro: Zahar, 1994.

FREUND, Julien. Sociologia de Max Weber. Rio de Janeiro: Forense Universitária, 2006.

FRANÇOIS, Chazel. Communauté politique, Etat et droit dans la sociologie wébérienne: grandeur et limites de l'entreprise. L'Année Sociologique. v. 59, n. 2, 2009, p. 275-301.

FURTADO, Celso. O longo amanhecer: reflexões sobre a formação do Brasil. Rio de Janeiro: Paz e Terra, 1999.

GIDDENS, Anthony. Em defesa da sociologia: ensaios, interpretações e tréplicas. São Paulo: UNESP, 2007.

HABERMAS, Jürgen. Direito e democracia: entre facticidade e validade. Rio de Janeiro: Tempo brasileiro, 1997

HALL, Stuart. A identidade cultural na pós-modernidade. Rio de Janeiro: DP\&A.

HESPANHA, Pedro. Mal-estar e risco social num mundo globalizado: novos problemas e novos desafios para a teoria social. In: SANTOS, Boaventura de Souza. Globalização: fatalidade ou utopia? Porto: Edições afrontamento, 2002.

KEYNES, Kohn Maynard. Teoria geral do emprego, do juro e do dinheiro. Rio de Janeiro: Editora Fundo de Cultura, 1970.

KING, Desmond S. O Estado e as estruturas sociais de bem-estar em democracias industriais avançadas. Revista Novos Estudos, n. 22, 1988, p. 53-76.

LIPIETZ, Alain. Audácia: uma alternativa para o século 21. São Paulo: Nobel, 1991.

MARCUSE, Herbert. Industrialização e capitalismo na obra de Max Weber. In: MARCUSE, Herbert. Cultura e sociedade. Vol. 2. São Paulo: Editora Paz e Terra, 1998.

MARSHALL, T. H. Cidadania, classe social e status. Rio de janeiro: Zahar Editores, 1967.

OFFE, Claus. Problemas estruturais do Estado capitalista. Rio de Janeiro: Tempo brasileiro, 1984.

OLIVEIRA, Francisco de. O surgimento do antivalor: capital, força de trabalho e fundo público. Revista Novos Estudos, n. 22, 1988, p. 8-28.

ROUANET, Sergio Paulo. As razões do iluminismo. São Paulo: Companhia das Letras, 1992.

SAINT-PIERRE, Héctor L. Max Weber: entre a paixão e a razão. Campinas: Editora da UNICAMP, 1999.

WEBER, Max. Conceitos básicos de sociologia. São Paulo: Editora Centauro, 2002.

WEBER, Max. História geral da economia. São Paulo: Centauro, 2006.

WEBER, Max. Ensaios de sociologia. Rio de Janeiro, LTC, 2008.

WEBER, Max. Escritos políticos. São Paulo: Martins Fontes, 2014.

WEBER, Max. Economia e Sociedade. Volume I. Brasília: Editora UNB, 2015/a.

WEBER, Max. Economia e Sociedade. Volume II. Brasília: Editora UNB, 2015/b. 